Acta Technologica Agriculturae 4

Nitra, Slovaca Universitas Agriculturae Nitriae, 2019, pp. 134-139

\title{
THE POSSIBILITIES OF USING ECOLOGICAL LIQUIDS IN TRIBOLOGICAL GLIDING SYSTEMS WITH A SELECTED SURFACE CREATED BY THE RADIAL WELDING TECHNOLOGY
}

\author{
František TÓTH ${ }^{1 *}$, Adam FÜRSTENZELLER ${ }^{1}$, Juraj RUSNÁK', Miroslav BOŠANSKÝ², Milan KADNÁR ${ }^{1}$ \\ ${ }^{1}$ Slovak University of Agriculture in Nitra, Slovak Republic \\ ${ }^{2}$ Slovak University of Technology in Bratislava, Institute of Transport Technology and Designing, Slovak Republic
}

\begin{abstract}
Presented paper deals with the issue of lubricating tribological systems formed by a double pair operating under mixed conditions of mixed friction before and after experimental tests, which were conducted in accordance with the selected methodology using Tribotestor M'06 test machine. The lubricating media included ecological oils Plantohyd $46 \mathrm{~S}$ by Fuchs and EAL Hydraulic 46 manufactured by the Mobil company. Applied ecological oils can be used in agricultural mobile machines as a replacement for conventional lubricants. The tests were conducted on designated material double pairs. The shaft was made of steel $16 \mathrm{MnCr} 5$. The second observed friction element in terms of glide angle test was a steel plate made of S235JR, gliding surface of which was produced utilizing flame powder coating technology. The results were statistically processed and are presented in the form of graphs, tables and figures.
\end{abstract}

Keywords: glide angle; flame powder welding; ecological oil; mixed friction; Tribotestor M’06

Agricultural engineering requires a constant improvement of operating life and reliability of machinery along with the possibility of using ecological oils. One option is to introduce new surface treatment technologies. This opens up a space for development and application of new unconventional surface treatment technologies with nontraditional additives and their specific properties (Bujna et al., 2016; Tillmann et al., 2017). Such technologies include radial welding technology.

Our current direction in this research field lies in analysis of the selected tribological properties of the material double pair, where one of the surfaces is modified by the radial welding technology. Biodegradable oil was selected as a lubricating medium for the gliding tribological system. Selection of biodegradable oils was performed on the basis of the experiments carried out under both laboratory and real conditions (Majdan et al., 2010; Kosiba et al., 2013; Stojilković and Kolb, 2016; Birkavs and Smigins, 2018; Kučera and Aleš, 2017).

\section{Material and methods}

Tribotestor M'06 (Fig. 1) was used for conducting the tribological experimental tests. This universal testing device enables the following types of tests to be carried out: limit load test (seizing test), limit speed test (speed seizing test), load capacity test (PV diagram determination), and durability test (longevity).
Experimental device consists of three main parts: the test part includes propulsion units for the rotational movement of the samples, vertical load force and measuring head; the second part includes a pneumatic circuit and all electronic devices; the last part is a control and evaluation unit in the form of a desktop computer allowing the triggering, controlling, managing, data collecting and evaluation of the test itself (Bijelića et al., 2017).

Experiment presented was carried out via the seizing test.

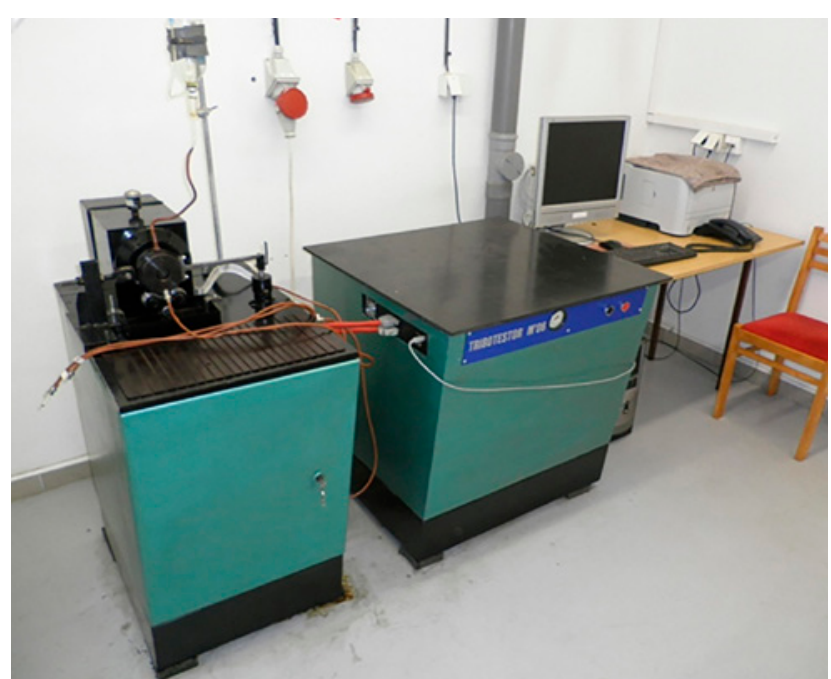

Fig. 1 Measuring device Tribotestor M'06

Contact address: František Tóth, Slovak University of Agriculture in Nitra, Faculty of Engineering, Department of Machine Design, Tr. Andreja Hlinku 2, 94976 Nitra, Slovak Republic, e-mail: frantisek.toth@uniag.sk 
The gliding system comprises four components (Stachowiak and Batchelor, 2014). The gliding double pair consists of a shaft and a gliding plate. The third element is a lubricating medium (ecological oil in this case). The fourth component is the surrounding environment. Atmosphere influence on the experiment was ignored because of relatively short duration of the experimental test. The first friction element was test shaft housing with $28 \mathrm{~mm}$ outer diameter and a length of $25 \mathrm{~mm}$, made of $16 \mathrm{MnCr} 5$ steel and pressed onto the cylindrical part of the support shaft (Bhushan, 2001). The support shaft was attached to a drive unit by means of a conical coupling via a tightening force through the internal thread in the conus. The second friction element was a steel plate made of S235JR in accordance with the STN EN 10027-1, with dimensions of $20 \times 20 \times 5 \mathrm{~mm}$ as the supporting material onto which the test glide surface was applied. It was made of NP 40, which is a NiBCrSi-based powder alloy (Chotěborský et al., 2013; Kučera and Chotěborský, 2013). The NP40 powder was applied to the surface of the plate via the flame powder welding technology. Welding process was carried out at the Department of Quality and Engineering Technologies of the Faculty of Engineering, Slovak University of Agriculture in Nitra. In general, the aforementioned powder is intended to weld the surfaces of steel components exposed to abrasive, corrosive and thermal stresses. Such layers can be machined by turning and grinding. For experiment presented, a gliding material was designed on the basis of results obtained by Tóth et al. (2014) and Kopiláková et al. (2017). The chemical composition and mechanical properties are shown in Table 1. Lubrication of the gliding elements and ecological oil test were performed by means of dipping; the oil was applied at the beginning of the experiment (Mang and Dresel, 2017).

Both gliding elements were weighed before and after the experiments utilizing the Voyager Pro VP $613 \mathrm{CN}$ precision scales and their roughness was measured by the Mitutoyo SJ-201 roughness meter. The monitored parameter was $R_{a}$ i its value represents the average arithmetic value of the absolute profile deviations at $n$ selected points of the profile at the base length. Using a Spectro analytical ferrograph (model T2FM), ferrograms were plotted for both double pairs. Their evaluation was performed utilizing the Carl Zeiss Axio Scope series microscope with a 1,000 times magnification.

Tested ecological product was Plantohyd $46 \mathrm{~S}$ by Fuchs; this product is an environmentally friendly, rapidly biodegradable, non-polluting hydraulic fluid based on synthetic esters of the HEES type according to the VDMA 24568 standard.

Plantohyd $46 \mathrm{~S}$ is compatible with materials commonly used in

Table 1 Chemical composition and mechanical properties of the NP 40 test plate

\begin{tabular}{|c|c|c|}
\hline Material & & \\
\hline \multirow{7}{*}{$\begin{array}{l}\text { Chemical } \\
\text { composition (\%) }\end{array}$} & $\mathrm{Ni}$ & rest \\
\hline & $\mathrm{Si}$ & $3.5-4.5$ \\
\hline & B & $1.5-2.5$ \\
\hline & $\mathrm{Cr}$ & $1.5-2.5$ \\
\hline & $\mathrm{Cu}$ & $\max .0 .3$ \\
\hline & $\mathrm{Fe}$ & $\max .0 .5$ \\
\hline & C & $\max .0 .1$ \\
\hline Physical properties & bulk density & $4.8 \mathrm{~g} \cdot \mathrm{cm}^{-3}$ \\
\hline \multirow{4}{*}{$\begin{array}{l}\text { Granulometric } \\
\text { composition (\%) }\end{array}$} & fraction $>0.100 \mathrm{~mm}$ & $\max .10$ \\
\hline & fraction $0.100 \mathrm{~mm}$ & $\max .90$ \\
\hline & fraction $0.063 \mathrm{~mm}$ & \\
\hline & fraction $<0.063 \mathrm{~mm}$ & \\
\hline
\end{tabular}

hydraulic systems. The base fluid and the additives used are toxicologically harmless. Fluid does not contain heavy metals and chlorine compounds; it is biodegradable up to more than $90 \%$ according to CEC-L-33-A-93.

This product can be used at temperatures ranging from $-30{ }^{\circ} \mathrm{C}$ to max. $90^{\circ} \mathrm{C}$. If the system temperature peaks at max. $95^{\circ} \mathrm{C}$, it is still acceptable in respect to the limit viscosity.

Plantohyd $46 \mathrm{~S}$ is versatile oil for use in all hydraulic and circulating systems requiring the use of ISO VG 46 oil. This product is suitable for mobile and stationary hydraulic systems. It is mainly used in devices operating in environments with a risk of leakage of hydraulic fluids that can endanger the ground, groundwater or surface water. If an oil leak occurs, this product will be mainly caught in the upper layers of soil, where it is rapidly biodegraded. Specific applications are mainly in construction, water management, agriculture and forestry.

The second used ecological liquid was the lubricant manufactured by Exxon Mobil under the trade designation EAL Hydraulic 46.

Mobil EAL Hydraulic 46 is hydraulic oil designed to meet the requirements of environmentally friendly hydraulic fluids. It is based on synthetic esters that are easily biodegradable. The additive complex provides environmental protection against wear and tear, high pressure, corrosion and ensures thermal stability. The resistance to oxidation helps prevent oil thickening and sediment formation even at high temperatures. This product can be used at temperature range from $-17^{\circ} \mathrm{C}$ to $\max .93^{\circ} \mathrm{C}$.

Mobil EAL Hydraulic 46 oil provides performance over a wide temperature range; its wear resistance, lubricating capabilities and lubricating film strength ensure adequate performance in hydraulic and circulating systems operating in mild and demanding operating conditions. Easy biodegradability and virtually non-toxic nature of this product allows usage in locations where leakage can have a negative impact on the environment. It is used in industry, forestry, water transport, and especially in mobile machinery. 
Table 2 Physical and chemical properties of used ecological lubricants

\begin{tabular}{|c|c|c|}
\hline & Fuchs Plantohyd 46 S & Mobil EAL Hydraulic 46 \\
\hline Class ISO-VG & 46 & 46 \\
\hline Viscosity index & 192 & 149 \\
\hline Viscosity at $40^{\circ} \mathrm{C}\left(\mathrm{mm}^{2} \cdot \mathrm{s}^{-1}\right)$ & 47.5 & 43.3 \\
\hline Viscosity at $100^{\circ} \mathrm{C}\left(\mathrm{mm}^{2} \cdot \mathrm{s}^{-1}\right)$ & 9.6 & 7.7 \\
\hline Density at $15^{\circ} \mathrm{C}\left(\mathrm{kg} \cdot \mathrm{m}^{-3}\right)$ & 922 & 930 \\
\hline Pour point $\left({ }^{\circ} \mathrm{C}\right)$ & -39 & -33 \\
\hline Flash point $\left({ }^{\circ} \mathrm{C}\right)$ & 290 & 298 \\
\hline
\end{tabular}

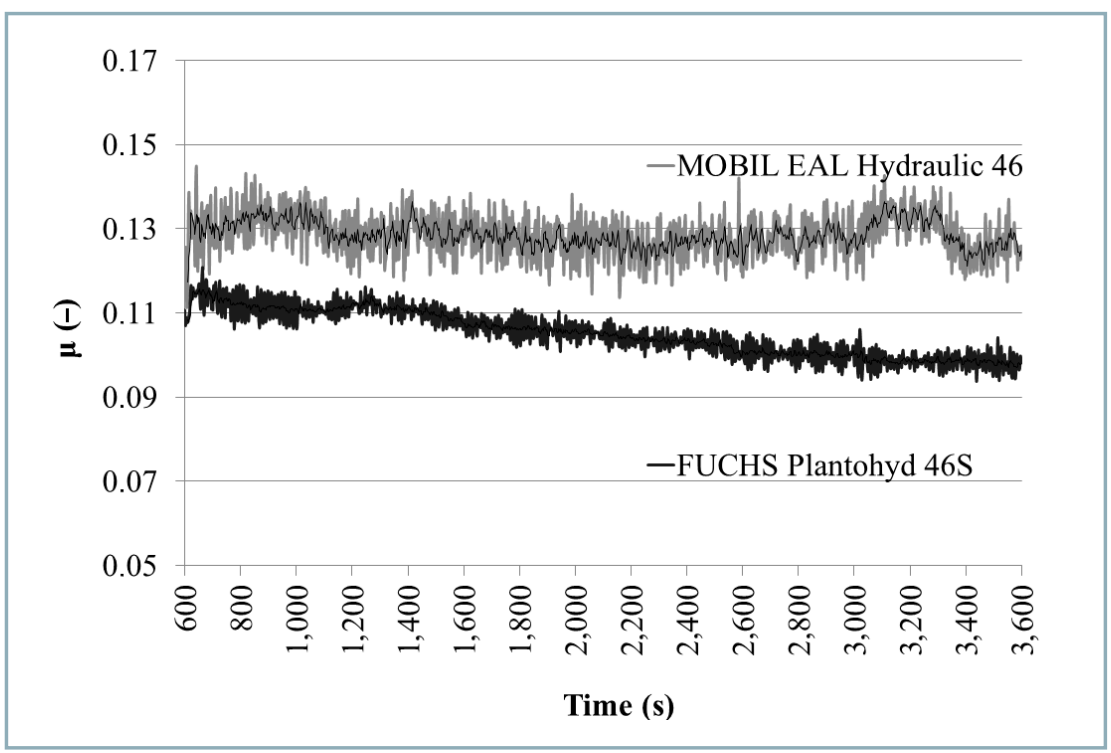

Fig. 2 Course of friction factors for ecological oils as a function of time

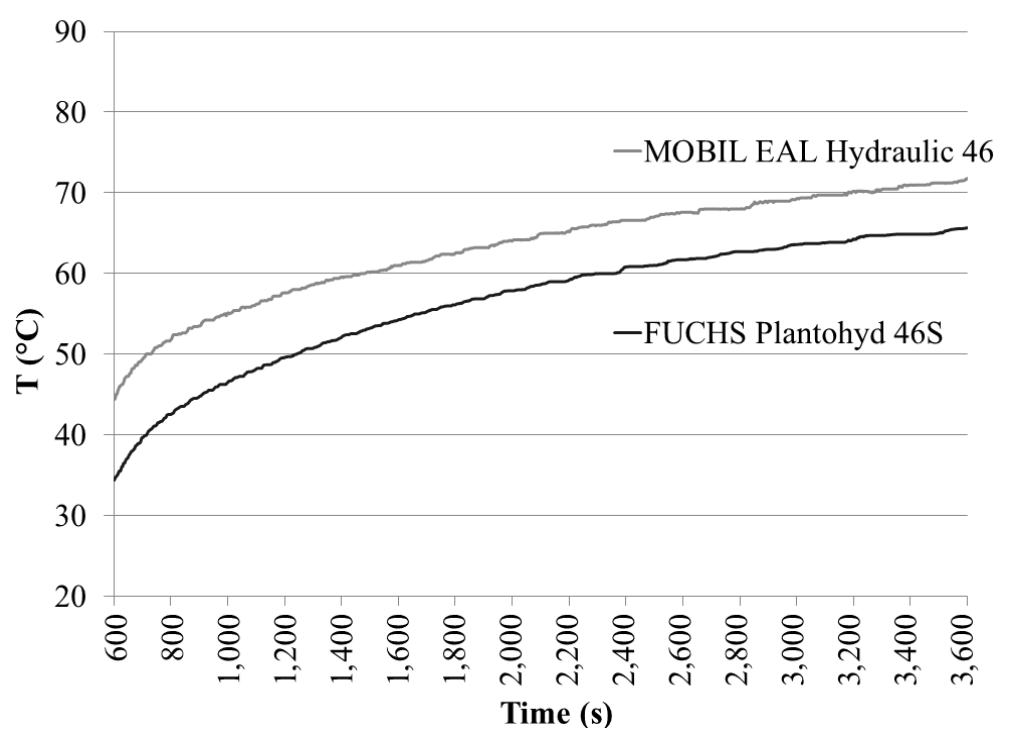

Fig. 3 Course of temperature for ecological oils as a function of time
During the experimental tests, the shaft speed was $180 \mathrm{rpm}$ in the clockwise direction. The test time was set to 3,600 seconds, with a 600 seconds start-up time and an hourly individual test. The load force was selected in the range from 500 to $3,000 \mathrm{~N}$. The start-up load was represented by an increment in the load force by increasing its value by $500 \mathrm{~N}$ every 120 seconds.

\section{Results and discussion}

Recorded results of laboratory measurements utilizing the Tribotestor M 06 experimental apparatus were statistically processed, and the dependences of friction and temperature coefficients on time, weight loss, roughness changes, and the elements contained in the lubricant medium were evaluated after test completion.

By statistical adjustment of the values recorded during the course of experimental tests, an overview of the development of the friction coefficients of two investigated ecological lubricants as a function of time was obtained. Fig. 2 illustrates the aforementioned stresses at a constant load force; the start-up time was not taken into consideration. It is obvious that the dependence of the friction factors on time is different for both investigated oils. Fuchs Plantohyd $46 \mathrm{~S}$ ecological oil shows a more balanced, decreasing curve from the initial value of 0.11 to 0.098 at the end of tests. Considering the Mobil EAL Hydraulic 46 ecological oil, there is a clear imbalance in the individual experimental tests, which is reflected in the larger scattering of the friction coefficient curve. The initial value of the friction coefficient is 0.13 during the experimental test and it merely slightly decreases to the final value of 0.125 . Both ecological oils are sensitive to the change in load what can actually be observed after reaching the final load value.

Temperature-dependent time course shown in Fig. 3 has the same character for both ecological oils. Mobil EAL Hydraulic 46 ecological oil showed a higher initial temperature of $44{ }^{\circ} \mathrm{C}$, as well as a higher final temperature of $71.5{ }^{\circ} \mathrm{C}$. The initial value of the Fuchs Plantohyd $46 \mathrm{~S}$ 
Table 3 Values of average weight loss

\begin{tabular}{|c|c|c|c|c|c|c|c|}
\hline \multicolumn{8}{|c|}{ Weight loss (g) } \\
\hline \multirow[t]{2}{*}{ Lubricants } & \multirow{2}{*}{$\begin{array}{l}\text { Number of } \\
\text { experimental } \\
\text { test }\end{array}$} & \multicolumn{3}{|c|}{ Plate } & \multicolumn{3}{|c|}{ Shaft } \\
\hline & & $\begin{array}{c}\text { before } \\
\text { experiment }\end{array}$ & $\begin{array}{c}\text { after } \\
\text { experiment }\end{array}$ & difference & $\begin{array}{c}\text { before } \\
\text { experiment }\end{array}$ & $\begin{array}{c}\text { after } \\
\text { experiment }\end{array}$ & difference \\
\hline \multirow{8}{*}{ 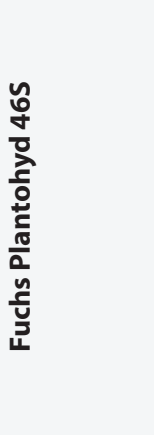 } & 1 & 20.924 & 20.929 & -0.005 & 405.249 & 405.245 & 0.004 \\
\hline & 2 & 19.652 & 19.655 & -0.003 & 398.810 & 398.798 & 0.012 \\
\hline & 3 & 22.305 & 22.309 & -0.004 & 392.630 & 392.616 & 0.014 \\
\hline & 4 & 21.676 & 21.679 & -0.003 & 399.053 & 399.044 & 0.009 \\
\hline & 5 & 22.836 & 22.841 & -0.005 & 405.817 & 405.804 & 0.013 \\
\hline & 6 & 19.952 & 19.949 & 0.003 & 395.862 & 395.854 & 0.008 \\
\hline & 7 & 18.766 & 18.768 & -0.002 & 398.593 & 398.590 & 0.003 \\
\hline & 8 & 20.661 & 20.665 & -0.004 & 402.736 & 402.730 & 0.006 \\
\hline Average & & & & -0.003 & & & 0.009 \\
\hline \multirow{2}{*}{ Lubricants } & \multirow{2}{*}{$\begin{array}{c}\text { Number of } \\
\text { experimental } \\
\text { test }\end{array}$} & \multicolumn{3}{|c|}{ Plate } & \multicolumn{3}{|c|}{ Shaft } \\
\hline & & $\begin{array}{c}\begin{array}{c}\text { before } \\
\text { experiment }\end{array} \\
\end{array}$ & $\begin{array}{c}\text { after } \\
\text { experiment }\end{array}$ & difference & $\begin{array}{c}\text { before } \\
\text { experiment }\end{array}$ & $\begin{array}{c}\text { after } \\
\text { experiment }\end{array}$ & difference \\
\hline \multirow{8}{*}{ 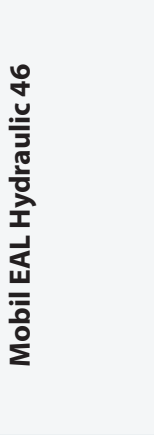 } & 1 & 20.356 & 20.354 & 0.002 & 404.927 & 404.921 & 0.006 \\
\hline & 2 & 19.770 & 19.768 & 0.002 & 407.332 & 407.321 & 0.011 \\
\hline & 3 & 19.298 & 19.296 & 0.002 & 397.844 & 397.839 & 0.005 \\
\hline & 4 & 19.039 & 19.040 & -0.001 & 401.636 & 401.627 & 0.009 \\
\hline & 5 & 20.752 & 20.751 & 0.001 & 410.088 & 410.080 & 0.008 \\
\hline & 6 & 19.567 & 19.568 & -0.001 & 399.780 & 399.770 & 0.010 \\
\hline & 7 & 20.156 & 20.155 & 0.001 & 399.075 & 399.067 & 0.008 \\
\hline & 8 & 19.958 & 19.957 & 0.001 & 411.446 & 411.437 & 0.009 \\
\hline Average & & & & 0.001 & & & 0.008 \\
\hline
\end{tabular}

ecological oil temperature was approx. $34^{\circ} \mathrm{C}$ and increased during the experiment to a final value of $65.5^{\circ} \mathrm{C}$. None of samples reached the maximum temperature allowed by the manufacturer during the experimental tests.

Voyager precision scales for VP $613 \mathrm{CN}$ illustrated the weight loss of the two gliding elements. Considering the material pair NP $40-16 \mathrm{MnCr} 5$, a specific phenomenon has arisen, when in the absolute value, the wear of the plate equals zero and potential plate weight increase results from either sticking, or welding of mechanical parts present in the lubricating environment due to the shaft adhesion wear. A similar phenomenon was observed in the previous experimental measurements performed at the workplace. The weight losses on the shafts for both used ecological oils were almost identical.

The roughness of the plate and the shaft were determined using dredger Mitutoyo SJ-201 roughness meter. The average change in roughness $R_{a}$ represents the change in surface roughness of the gliding element over the duration of experimental test. Considering the interaction of both ecological oils with the material pair $16 \mathrm{MnCr} 5$ - NP 40 , the shaft got smoother during the test, which was reflected by a decrease in the $R_{a}$ value of the $16 \mathrm{MnCr} 5$ and an increase in the $R_{a}$ value of the NP 40 composite plate. This phenomenon occurs due to either sticking, or welding of shaft mechanical parts to the composite plate. This phenomenon was confirmed by the weight loss analysis. The average drop in the roughness value of $R_{a}$ of the shaft was $0.371 \mu \mathrm{m}$ in case of the Plantohyd $46 \mathrm{~S}$ oil and $0.347 \mu \mathrm{m}$ in case of the EAL Hydraulic 46 oil. The increase in the average roughness value of $R_{a}$ of the plates was almost equal to $0.271 \mu \mathrm{m}$ (Plantohyd $46 \mathrm{~S}$ ) in comparison to $0.276 \mu \mathrm{m}$ (EAL Hydraulic 46).
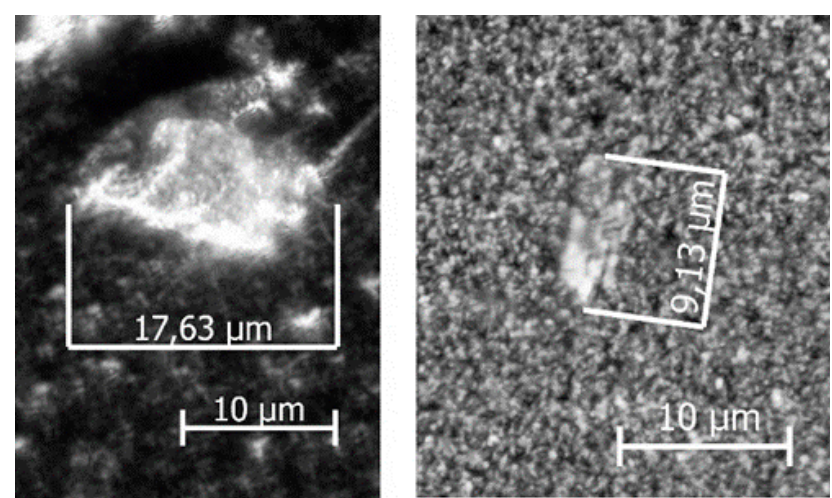

Fig. 4 Evaluation of ferrography of the ecological oil Fuchs Plantohyd 46 S (1,000 times magnification) 
Table 4 Average changes in $R_{a}$ roughness values

\begin{tabular}{|c|c|c|c|c|c|c|c|}
\hline \multicolumn{8}{|c|}{ ' $R_{a}^{\prime}$ change $(\mu \mathrm{m})$} \\
\hline \multirow[t]{2}{*}{ Lubricants } & \multirow{2}{*}{$\begin{array}{l}\text { Number of } \\
\text { experimental } \\
\text { test }\end{array}$} & \multicolumn{3}{|c|}{ Plate } & \multicolumn{3}{|c|}{ Shaft } \\
\hline & & $\begin{array}{c}\text { before } \\
\text { experiment }\end{array}$ & $\begin{array}{c}\text { after } \\
\text { experiment }\end{array}$ & change & $\begin{array}{c}\text { before } \\
\text { experiment }\end{array}$ & $\begin{array}{c}\text { after } \\
\text { experiment }\end{array}$ & change \\
\hline \multirow{8}{*}{ 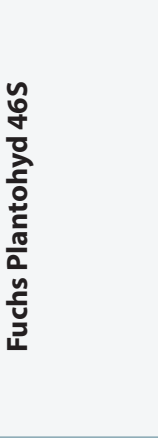 } & 1 & 0.355 & 0.660 & 0.305 & 0.815 & 0.620 & -0.195 \\
\hline & 2 & 0.340 & 0.520 & 0.180 & 1.025 & 0.685 & -0.340 \\
\hline & 3 & 0.190 & 0.545 & 0.355 & 0.960 & 0.600 & -0.360 \\
\hline & 4 & 0.220 & 0.490 & 0.270 & 0.935 & 0.565 & -0.370 \\
\hline & 5 & 0.175 & 0.490 & 0.315 & 1.220 & 0.760 & -0.460 \\
\hline & 6 & 0.300 & 0.285 & -0.015 & 1.190 & 0.835 & -0.355 \\
\hline & 7 & 0.350 & 0.660 & 0.310 & 1.070 & 0.675 & -0.395 \\
\hline & 8 & 0.260 & 0.710 & 0.450 & 1.175 & 0.680 & -0.495 \\
\hline Average & & & & 0.271 & & & -0.371 \\
\hline & \multirow{2}{*}{$\begin{array}{l}\text { Number of } \\
\text { experimental } \\
\text { test }\end{array}$} & \multicolumn{3}{|c|}{ Plate } & \multicolumn{3}{|c|}{ Shaft } \\
\hline & & $\begin{array}{c}\text { before } \\
\text { experiment }\end{array}$ & $\begin{array}{c}\text { after } \\
\text { experiment }\end{array}$ & change & $\begin{array}{c}\text { before } \\
\text { experiment }\end{array}$ & $\begin{array}{c}\text { after } \\
\text { experiment }\end{array}$ & change \\
\hline \multirow{8}{*}{ 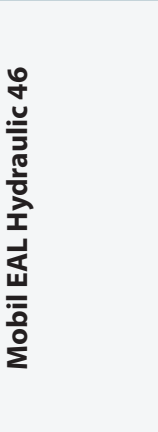 } & 1 & 0.350 & 0.650 & 0.300 & 0.920 & 0.550 & -0.370 \\
\hline & 2 & 0.300 & 0.490 & 0.190 & 0.850 & 0.450 & -0.400 \\
\hline & 3 & 0.480 & 0.980 & 0.500 & 0.990 & 0.600 & -0.390 \\
\hline & 4 & 0.260 & 0.360 & 0.100 & 0.760 & 0.570 & -0.190 \\
\hline & 5 & 0.580 & 0.870 & 0.290 & 0.850 & 0.395 & -0.455 \\
\hline & 6 & 0.330 & 0.580 & 0.250 & 0.790 & 0.450 & -0.340 \\
\hline & 7 & 0.410 & 0.780 & 0.370 & 0.690 & 0.510 & -0.180 \\
\hline & 8 & 0.390 & 0.595 & 0.205 & 1.080 & 0.630 & -0.450 \\
\hline Average & & & & 0.276 & & & -0.347 \\
\hline
\end{tabular}

The ferrography of the ecological oil Plantohyd $46 \mathrm{~S}$ is given in Fig. 4; left figure shows well visible iron particles found at the start of the ferrography. On the basis of their size and comparison with the sample of non-ferrous particles, this wear was characterized at the upper limit of adhesive wear with $17.63 \mu \mathrm{m}$ in size. Right figure (Fig. 4) shows a nonferrous, non-ferrite particle with a size of $9.13 \mu \mathrm{m}$.

Fig. 5 presents the ferrography analysis of the ecological oil EAL Hydraulic 46. Left figure depicts a $19.35 \mu \mathrm{m}$ iron particle that defines the borderline adhesive wear. The
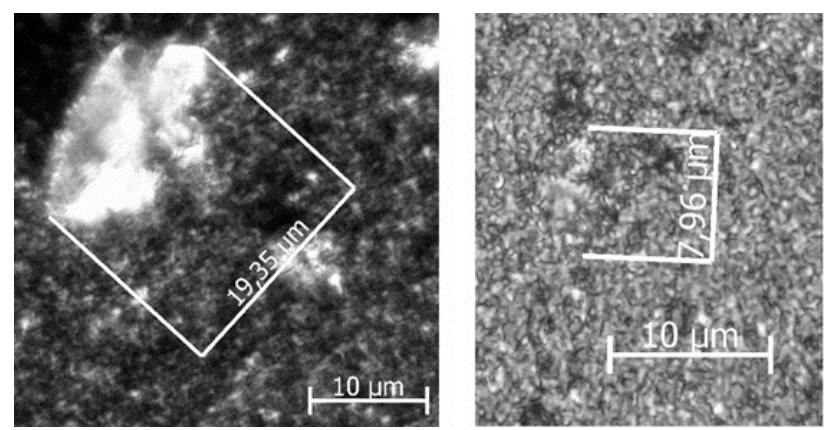

Fig. 5 Evaluation of ferrography of the ecological oil Mobil EAL Hydraulic 46 (1,000 times magnification) particle in question is likely chrome captured in the top of the ferrography. Right figure (Fig. 5) illustrates the lower part of the ferrography, showing the non-ferrous particle resulting from adhesive wear with approximately $8 \mu \mathrm{m}$ in size.

As far as both ecological oils are concerned, particles have a lamellar shape indicating their multiple passages through the contact surface of the friction elements.

\section{Conclusion}

Presented scientific paper analyses the effect of selected ecological oils on the tribological system consisting of a gliding double pair during an experiment conducted on the basis of the proposed methodology. Comparison of the dependence development of the friction coefficients of ecological oils on time proved that Fuchs Plantohyd $46 \mathrm{~S}$ shows more appropriate and balanced course. The ecological oil temperature dependence showed a very similar profile with a lower oil temperature of Fuchs Plantohyd $46 \mathrm{~S}$. Neither of investigated oils reached the maximum temperature limiting its use during the experiment. Specific phenomenon in weight loss arose - in the absolute value, the wear of the plate equals zero and potential plate weight increase results from the sticking or welding of mechanical parts present in 
the lubricating environment due to the shaft adhesion wear. The wear of the shafts was approximately the same for both investigated oils. The results obtained reflect the conditions of the experiment itself when the gliding pair works in a lubricating bath without the possibility of oil filtration. Another indicator taken into account was the change in roughness of investigated surfaces. The roughness was evaluated through the $R_{a}$ characteristic, which was measured before and after the experiment on the contact surfaces of the gliding elements. Considering both ecological oils, the shaft got smoother during the test, which was reflected by a decrease in the $R_{a}$ value and an increase in the $R_{a}$ value in relation to the NP40 composite plate. In this respect, the Mobil EAL Hydraulic 46 ecological oil showed better results. Previous values were also confirmed by the ferrography of the gliding pairs in question. Thereby it was proved that these ecological oils are fully usable under real operating conditions (when oil cooling and filtration are ensured) and utilization of the NP 40 composite material does not represent an obstacle (Kučera and Tkáč, 2010; Kučera et al., 2016; Kosiba et al., 2016).

\section{Acknowledgements}

The contribution has been prepared within the solving of scientific grant project VEGA 1/0227/15 Study of tribological characteristics of the new high hard coatings on materials suitable for gearings.

\section{References}

BHUSHAN, B. 2001. Modern Handbook of Tribology. Boca Raton : CRC Press, 1760 pp. ISBN 0-8493-8403-6.

BIJELIĆA, I. - MOR, N. - ŽIVKOVIĆ, M. - TUBIN, V. - STOŽINIĆ, T. 2017. The influence of the contact pressure on the value of the coefficient of friction. In Tribology in Industry, vol. 39, no. 2, pp. 255-259.

BIRKAVS, A. - SMIGINS, R. 2018. Experimental research on compatibility of mineral and biobased hydraulic oils. In Agronomy Research, vol. 16, no. S1, pp. 968-976.

BUJNA, M. - PRÍSTAVKA, M. - DOSTÁL, P. - KORENKO, M. - KADNÁR M. 2016. Influence of roughness on quality molybdenum deposit layer by thermal spraying. In Acta Universitatis Agriculturae et Silviculturae Mendelianae Brunensis, vol. 64, no. 1, pp. 9-14.

CHOTĚBORSKÝ, R. - KUČERA, M. - HERÁK, D. 2013. Effect of the welding parameters on the hardfacing abrasive wear. In Scientia Agriculturae Bohemica, vol. 44, no. 4, pp. 232-236.
KOPILÁKOVÁ, B. - TURZA, J. - HUJO, L’. - KOSIBA, J. 2017. Evaluation of hydraulic resistance in various liquids and temperature. In Tribology in Industry, vol. 39, no. 1, pp. 129-135.

KOSIBA, J. - ČORNÁK, Š. - GLOS, J. - JABLONICKÝ, J. - VOZÁROVÁ, V. - PETROVIĆ, A. - CSILLAG, J. 2016. Monitoring oil degradation during operating tests. In Agronomy Research, vol. 14, no. 5, pp. 1626-1634.

KOSIBA, J. - HUJO, L. - TULÍK, J. - RAŠO, M. 2013. Study of the impact of synthetic fluid on the lifetime of hydraulic pump. In Advanced Materials Research, vol. 801, pp. 7-12.

KUČERA, M. - ALEŠ, Z. 2017. Morphology analysis of friction particles generated in tractor transmission oils. In Acta Technologica Agriculturae, vol. 20, no. 3, pp. 57-62.

KUČERA, M. - CHOTĚBORSKÝ, R. 2013. Analysis of the process of abrasive wear under experimental conditions. In Scientia Agriculturae Bohemica, vol. 44, no. 2, pp. 102-106.

KUČERA, M. - ALEŠ, Z. - PAVLŮ, J. - HNILICOVÁ, M. 2016. Applying of automatic laser particle counter as technique to morphology assessment and distribution of wear particles during lifetime of transmission oils. In Key Engineering Materials, vol. 669, pp. 417-425.

KUČERA, M. - TKÁČ, Z. 2010. Analysis of biodegradable oil on synthetic basis in a variable displacement axial piston pump of swash plate. In Acta Facultatis Technicae, vol. 15, no. 1, pp. 81-88.

MAJDAN, R. - TKÁČ, Z. - TULÍK, J. - KOSIBA, J. - ZIGIŇ, P. - BUREŠ, L. 2010. Evaluation of ecological hydraulic fluid tests based on the flow efficiency of the hydrogenator. In Acta Technologica Agriculturae, vol. 13, no. 3, pp. 61-64.

MANG, T. - DRESEL, W. 2017. Lubricants and Lubrication. Weinheim : WILEY-VCH Verlag GmbH \& Co. KGaA, 1262 pp. ISBN 3-540-41909-8. STACHOWIAK, G. - BATCHELOR, A. 2014. Engineering Tribology. Oxford : Butterworth-Heinemann, 884 pp. ISBN 0-7506-7836-4.

STOJILKOVIĆ, M. - KOLB, M. 2016. Tribological properties of biodegradable universal tractor transmission oil. In Tribology in Industry, vol. 38, no. 2, pp. 229-234.

STN EN 10027-1. 2018. Designation systems for steels. Part 1: Steel names.

TILLMANN, W. - HAGEN, L. - KOKALJ, D. 2017. Spray characteristics and tribo-mechanical properties of high-velocity arc-sprayed WCW2C iron-based coatings. In Journal of Thermal Spray Technology, vol. 26, no. 7, pp. 1685-1700.

TÓTH, F. - RUSNÁK, J. - BELOEV, H. I. - KADNÁR, M. - PÁLEŠ, D. 2014. The study of geometrical changes of a given sliding couple caused by the influence of operation. Ruse : Angel Kanchev University of Ruse, 82 pp. ISBN 978-954-712-628-2. 